Paired Comparison Product Testing When Individual Preferences are Stochastic Author(s): B. Wierenga

Source: Applied Statistics, Vol. 23, No. 3, (1974), pp. 384-396

Published by: Blackwell Publishing for the Royal Statistical Society

Stable URL: http://www.jstor.org/stable/2347130

Accessed: 11/06/2008 08:56

Your use of the JSTOR archive indicates your acceptance of JSTOR's Terms and Conditions of Use, available at http://www.jstor.org/page/info/about/policies/terms.jsp. JSTOR's Terms and Conditions of Use provides, in part, that unless you have obtained prior permission, you may not download an entire issue of a journal or multiple copies of articles, and you may use content in the JSTOR archive only for your personal, non-commercial use.

Please contact the publisher regarding any further use of this work. Publisher contact information may be obtained at http://www.jstor.org/action/showPublisher?publisherCode=black.

Each copy of any part of a JSTOR transmission must contain the same copyright notice that appears on the screen or printed page of such transmission.

JSTOR is a not-for-profit organization founded in 1995 to build trusted digital archives for scholarship. We enable the scholarly community to preserve their work and the materials they rely upon, and to build a common research platform that promotes the discovery and use of these resources. For more information about JSTOR, please contact support@jstor.org. 


\title{
Paired Comparison Product Testing when Individual Preferences are Stochastic
}

\author{
By B. WIERENGA \\ Agricultural University, Wageningen, Netherlands
}

[Received February 1973. Revised August 1973]

\section{SUMMARY}

The preference of an individual in a paired comparison product test is stochastic, i.e. the probability $p$, that he will prefer one of the two alternatives, is not 0 or 1 , but lies somewhere between these values. It is shown that the distribution of $p$, when approximated by a beta distribution, can be obtained by means of a replicated paired comparison product test.

Keywords: PRODUCT TEST; PAIRED COMPARISON; STOCHASTIC PREFERENCE; PREFERENCE DISTRIBUTION; BETA DISTRIBUTION

\section{INTRODUCTION}

IN this paper, we consider paired comparison product tests (to be described as product tests) in which the outcome of each individual preference test is a random 0-1 variate, where each individual has his own probability distribution over the two possible outcomes.

First, we will show that this probabilistic concept of individual preferences-as opposed to a deterministic one where every individual is supposed to make always the same choice-reflects reality as is demonstrated by empirical results.

We then investigate advantages of knowing more about the preference distribution than just the proportion of the population preferring one of the alternatives.

It will be shown that, when a beta distribution is assumed for the distribution of preference in the population, its parameters, which can provide useful information about the preference situation, can be estimated by means of an extension of a paired comparison product test.

The procedure for doing this is demonstrated for empirical data.

\section{Paired Comparison Product Tests}

In a paired comparison product test, two products (throughout this text to be designated $A$ and $B$ ) are successively presented to randomly selected subjects. No information is given to the subject about the identity of the products (e.g. brand names) to prevent possible prejudice. After having observed (e.g. tasted or smelled) the two alternatives, every subject is asked which of the two he (or she) prefers. Because the order in which the two products are presented might influence the answers, this order is alternated throughout the test.

If ties are not permitted (forced choice) there are two possible answers for each subject: $A$ and $B$. If a statement of no preference is permitted, there are three outcomes: $A, B$ and $N$ (neutral). In the latter situation, we can still summarize these in the two possibilities: $A$ and $\bar{A}$, where $\bar{A}$ means that either $B$ or $N$ was chosen, and not $A$. It will be clear that by subsequent dichotomization the number of $A$-preferers 
as the outcome of the test may be different from the number which would have been found if the subject could only choose between " $A$ preferred" or " $B$ preferred". The effect of the so-called neutral vote is a well-known problem in marketing research.

Every subject is said to be either an $A$-preferer or an $\bar{A}$-preferer. It is indifferent which of the two alternatives is called $A$. In a forced-choice test $\bar{A}$ and $B$ coincide.

The purpose of this kind of testing is to draw conclusions about the preferenceswith respect to the two products in question-in the population, on the basis of the sample of persons in the product test. The population is the one in which we are interested with regard to the particular product (target population), and the subjects must be drawn from that population.

Paired comparison product tests are carried out for products judged on a number of different dimensions, i.e. products for which a subject considers a number of different features. Such features may be: shape, package, colour, smell, taste, etc., but other kinds of psychological connotations may also play a role. If a product is judged on only one dimension and one wishes to have the relative preference for one out of two alternatives of the product, it is possible to have each alternative judged by a separate sample of subjects, who produce rating scores for each alternative. From these rating scores, relative preferences can subsequently be established. When judgments are multidimensional, however, the approach of letting each product be judged separately leads to difficulties. It would be necessary to have a subject's opinion on a number of attributes, but often it will not be clear which attributes to include. It is also difficult to determine the weights of the different attributes relative to each other. One method would be to ask a subject's general appreciation of a product, but then the problem is that a subject may focus on one specific attribute or make a comparison with a specific product known to him. In this case, however, the reference-base of the judgment is not known and different subjects may apply different reference-bases. Therefore, in cases of multidimensional judgments, paired comparison product tests are often used in which products are directly compared with each other.

\section{Stochastic vs Deterministic ApProach}

The usual procedure after the completion of the product test is to compute the fraction of subjects who preferred $A$. The "true" fraction of $A$-preferers in the population can be called $p_{A}$. Every subject can be seen as a drawing from a Bernoulli distribution with parameter $p_{A}$. The number of subjects who prefer $A$ in a product test with sample size $n$ is then a binomial random variate with parameters $p$ and $n$. On the basis of the computed fraction of $A$-preferers in the sample, a confidence region for $p_{A}$ can be obtained in the usual way. Because it is assumed that the population contains only people who choose with probability one either $A$ or $\bar{A}$ this can be called a deterministic approach.

However, the stimuli produced by the two alternatives offered to the subject are in general random variates, and the outcome of the comparison will not be fixed but stochastic, see Thurstone, as quoted by David (1963, chapter 1). Generally, a subject does not have a probability 0 or 1 to prefer $A$, but this probability lies somewhere between these two values. When the choice situation for the individual subject is considered in this way we can say that a stochastic approach is followed.

Day (1965) has also proposed the concept of stochastic preference, by suggesting that a person has a preference for $A$ if his probability to choose $A$ in a pairwise comparison product test is greater than $0 \cdot 5$. 


\section{Empirical Support for the Stochastic Approach}

It is useful to know if in product test situations subjects are consistent when asked to make repeated choices between the same two products. According to the deterministic view they would not change at all; in the stochastic view a certain number of changes is likely.

We have the results of 12 product tests, which were provided by SOCMAR N.V., in Rotterdam.

The products in the test were:

Tests 1-3: a deep-frozen dessert product.

Test 4: beer.

Tests 5-7: margarine.

Tests 8-10: bread.

Tests 10-12: biscuits.

In each of the 12 tests there were two alternatives: $A$ and $B$. A subject was allowed to choose from three possibilities:

$$
A \text { preferred; } B \text { preferred; No preference }(N) \text {. }
$$

Every subject was submitted twice to the same test, with a time interval varying from some hours to some days. The order of presentation was varied throughout the test, and the subjects were not told that the alternatives in the second test were the same as those of the first one.

The results of the tests with respect to change in preference are presented in Table 1.

TABLE 1

Fractions of preference changers in 12 product tests for two different definitions of preference change

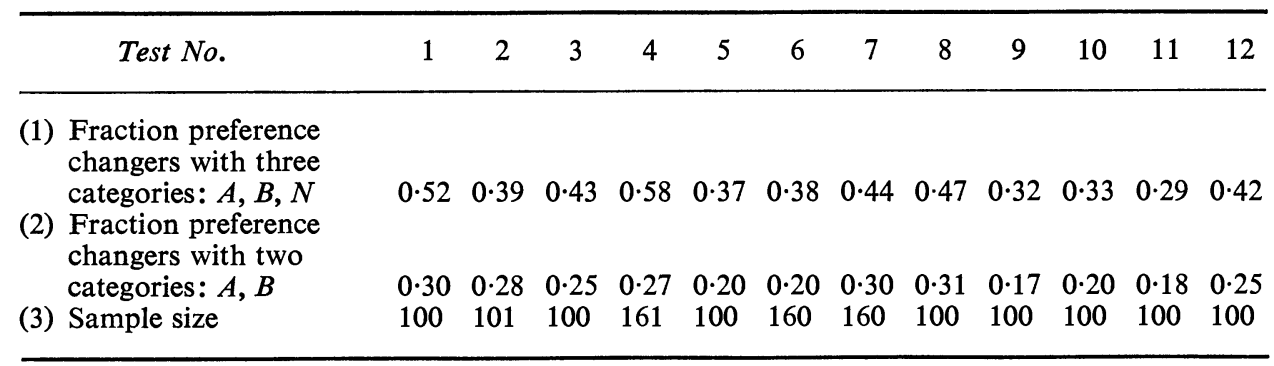

We can define preference change in different ways:

(1) When we consider the three possible answers $A, B$ and $N$ as separate preference categories, we say that a person changed preference if his answers at the two occasions belong to different preference categories. In row (1) of Table 1, one finds the number of preference changers thus defined, expressed as a fraction of the total number of subjects in each test. We see that preference changing is quite considerable: the fraction ranges from 0.29 to 0.58 with a median of 0.41 . So about 40 per cent of the subjects changed preference. 
(2) We can also take the position that a change (vice versa) from $A$ to $N$ or from $B$ to $N$ is less impressive than from $A$ to $B$. Thus we may restrict the meaning of preference changing to changes from $A$ to $B$ and $B$ to $A$. We report the number of subjects who changed preference defined in this way in row (2) of Table 1 (again as a fraction of the total number of subjects). Now the fraction preference changers ranges from $0 \cdot 17$ to $0 \cdot 31$. In this more restricted concept of preference change, the change is still substantial.

Thus, the empirical data suggest that a stochastic interpretation of individual preference choice is more appropriate than a deterministic one.

\section{The Preference Distribution}

From now on our concept is that every person in the population has a certain probability to prefer alternative $A$ in a product test. We call this probability $p$. So:

$$
\begin{gathered}
p=\operatorname{Prob}(A \text { preferred in a pairwise comparison product } \\
\text { test with alternatives } A \text { and } B) .
\end{gathered}
$$

We assume that different persons may have different $p$ 's, so we state that $p$ is distributed in the whole population in a certain way and we call the probability density function (p.d.f.) of $p: g(p)$. For example, $g(p)$ may have the form as designed in Fig. 1 (because $p$ is a chance, $p$ can only take values in the interval $[0,1]$ ).

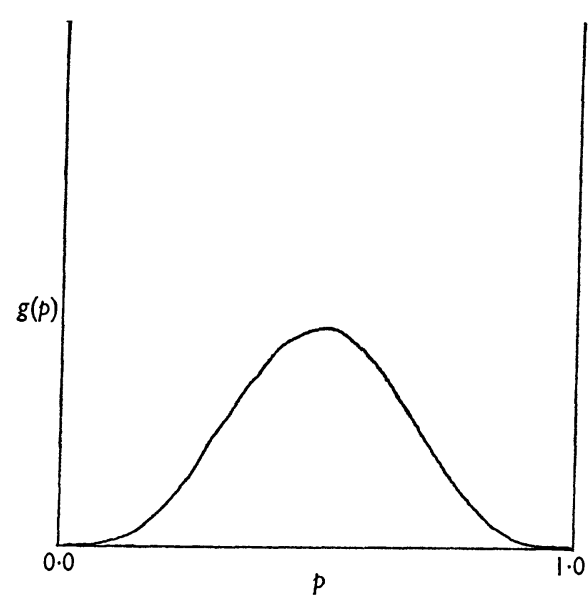

FIG. 1. A possible pdf of $p$.

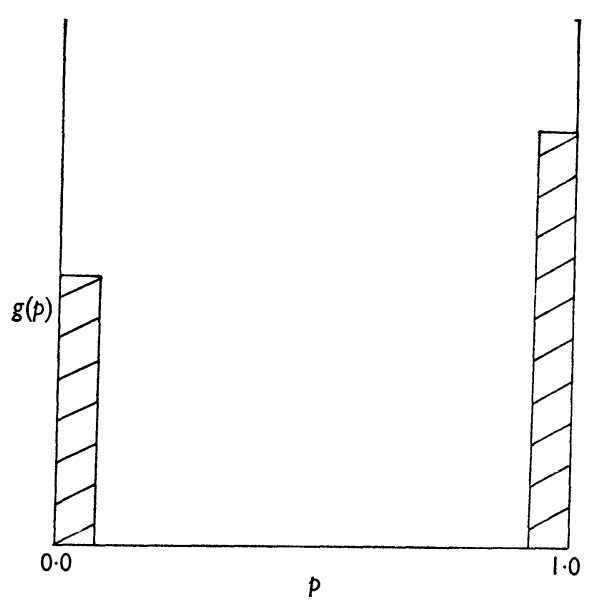

FIG. 2. A special case: the probability mass (shaded) is concentrated at the extremes.

A special case arises when the probability mass is fully concentrated at the extremes 0 and 1 (see Fig. 2). When this happens we are back into the deterministic situation described in Section 3, so this is a special case in the stochastic approach.

It might be remarked that it makes no difference to the product test outcomes if the situation is

(a) $p$ is distributed in the population according to the density function $g(p)$, with expected value $\mu_{1}$, or

(b) the population consists only of fully determined persons who prefer, with probability $1, A$ or $\bar{A}$ and the fraction of people who prefer $A$ is $m \mu_{1}$. 
In case (a) the probability that a randomly selected person will prefer $A$ is

$$
\int_{0}^{1} p g(p) \mathrm{d} p=\mu_{1}
$$

while in situation (b) the probability to draw an $A$-preferer is also $\mu_{1}$. Because the probability distribution for the individual outcome is the same for the two situations, this also holds for the results of the whole test.

This being true, it is important for a (potential) seller or producer of a product to know how the preference for his product is structured: how many people are there with a strong preference for his product and how many with a preference for the other product. In other words: it is desirable to have more information about the distribution of $p$, in addition to an estimate of its expectation from the usual product test.

\section{The Use of the Beta Distribution}

To be able to work with $g(p)$, i.e. the distribution of $p$ in empirical situations, one has to assume a special form for this distribution. Because the preference situation can take most possible forms, in practice a distribution with a great flexibility is needed and we therefore propose the beta distribution.

The beta distribution has two parameters, here indicated as $a$ and $b(a, b>0)$, and we express the beta distribution of $p$ in the population as follows:

$$
p \simeq \beta(a, b) \text {. }
$$

The density function can take the U-form $(0<a, b \leqslant 1)$, the inverse U-form $(a, b>1)$, the J-form $(0<b \leqslant 1<a)$, the inverse J-form $(0<a \leqslant 1<b)$ and the rectangular form $(a=b=1)$ (see Day, 1965, pp. 150,151). Further advantages of the beta distribution are:

Only values from 0 to 1 can be taken, which is a necessary condition for the probability $p$.

Rather simple expressions for the moments.

This is not the first time that the beta distribution is used for modelling choice behaviour of a population in a marketing context; in some brand choice models, the beta distribution is used to describe the distribution in the population of the probability to choose a certain brand. For instance, Howard (1968) used it in his Dynamic Inference Model, Aaker (1971) in his New Trier Model, and Massy, Montgomery and Morrison (1970) discuss the wide variety of forms the beta distribution can take for describing population heterogeneity in brand choice processes. A limitation is that when the preference situation is not unimodal, the fit by the beta distribution may be less good.

The probability density function of the beta distribution with parameters $a$ and $b$ is

$$
b(x)=\frac{1}{B(a, b)} x^{a-1}(1-x)^{b-1} \quad(0 \leqslant x \leqslant 1),
$$

where $B(a, b)$ is the well-known beta function with parameters $a$ and $b$. We define

$$
\mu_{i}=\operatorname{Ex}^{i} \quad(i=1,2, \ldots) .
$$


Then for the moments we have

$$
\begin{aligned}
& \mu_{1}=\frac{a}{a+b} \\
& \mu_{2}=\frac{a(a+1)}{(a+b)(a+b+1)}
\end{aligned}
$$

and, generally,

$$
\mu_{i+1}=\mu_{i}\left(\frac{a+i}{a+b+i}\right) \quad(i=1,2, \ldots) .
$$

With the aid of the beta distribution, we can now give a numerical example to show the importance of knowledge about the distribution of $p$ in addition to the expected value $\mu_{1}$, estimated in a conventional product test.

Imagine the three following cases (in all three situations there is a choice situation with products $A$ and $B, p$ is the probability to prefer $A$, and $p$ is distributed in the population according to a beta distribution):

$$
\begin{array}{ll}
\text { Case I } & p \simeq \beta(28 \cdot 2,18 \cdot 8), \\
\text { Case II } & p \simeq \beta(3 \cdot 0,2 \cdot 0), \\
\text { Case III } & p \simeq \beta(0 \cdot 4286,0 \cdot 2857) .
\end{array}
$$

In all these cases $E p=\mu_{1}=a /(a+b)=0 \cdot 60$, so in a product test the three situations would all lead to a fraction $A$-preferers of 0.60 . But as is shown in the Figs 3-5, where the density functions are plotted, the preference situations are by no means identical. In Case I almost all persons have a preference for $A$ slightly over 0.50 ; in Case II there are a number of persons who have a rather high probability of preferring $A$; and in Case III a high proportion of the population consists of either strong approvers or strong disapprovers of $A$. From a marketing point of view, these differences seem to be important, for instance to the seller of product $A$, when $B$ is supposed to be a competing brand. One could say that in Case $\mathrm{I}$ the situation is rather dangerous

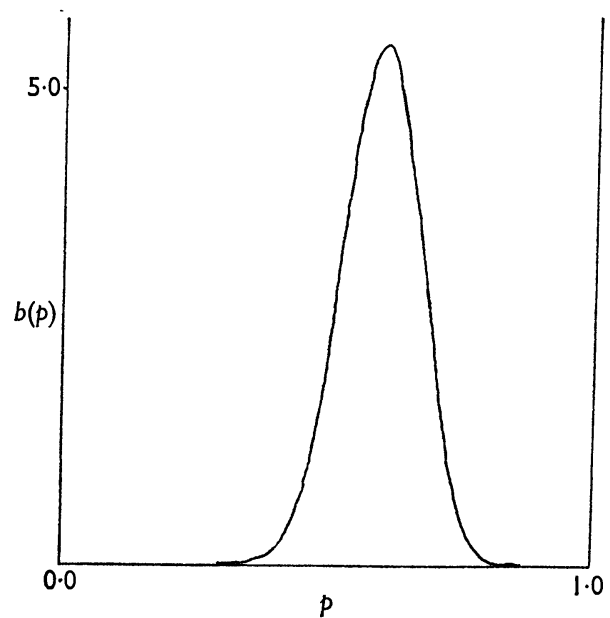

FIG. 3. Case I: $p \simeq \beta(28 \cdot 2,18 \cdot 8)$.

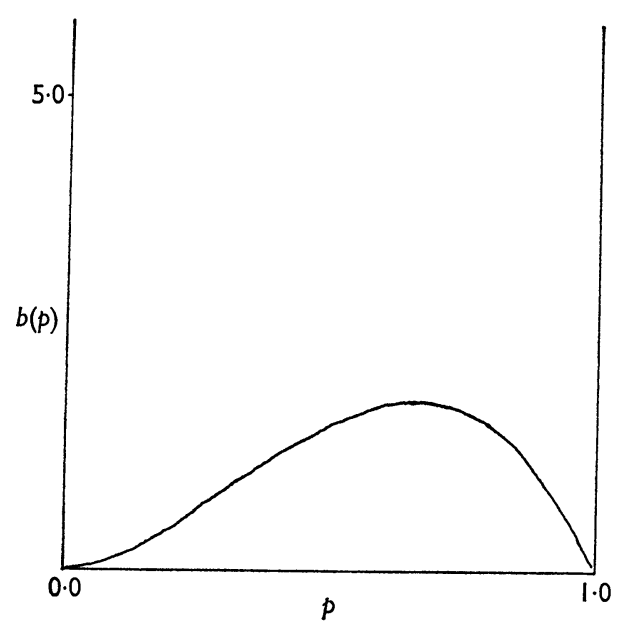

FIG. 4. Case II: $p \simeq \beta(3 \cdot 0,2 \cdot 0)$. 
because a slight change might convert the weak approvers of $A$ to disapprovers. In Case III, however, product $A$ has a considerable part of the population rather firmly tied to itself, which seems to be a decidedly comfortable situation.

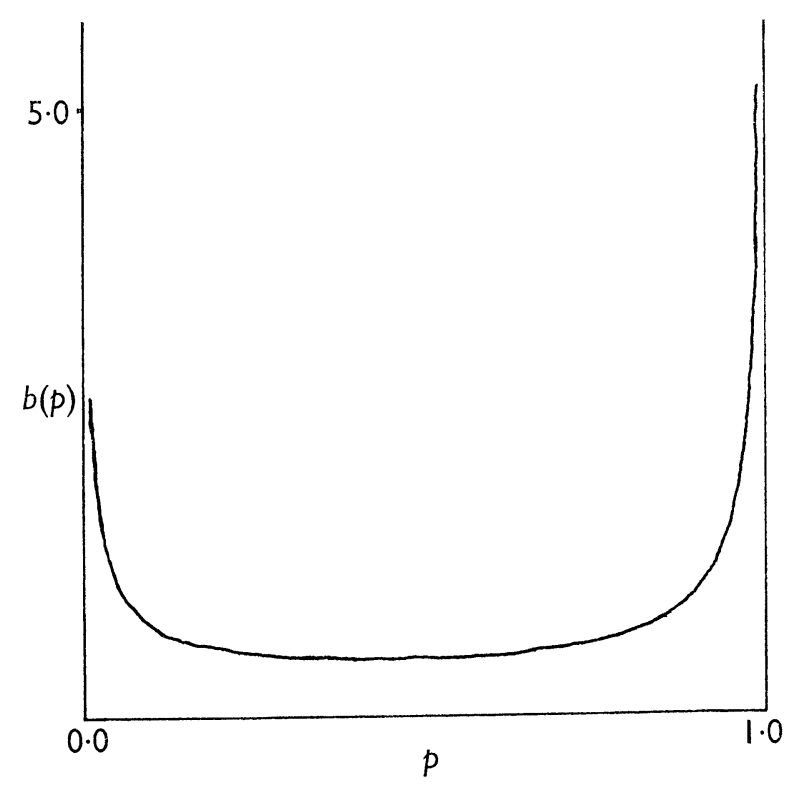

FIG. 5. Case III : $p \simeq \beta(0 \cdot 4286,0 \cdot 2857)$.

This can be illustrated in another way. We define a person to be a net $A$-preferer if his probability to choose $A$ is greater than 0.5 , a strong $A$-prefer if greater than $0 \cdot 75$, a strong $\bar{A}$-preferer if $P \leqslant 0 \cdot 25$. (Of course these boundaries are somewhat arbitrary.) We can compute now for each case the percentages of net $A$-preferers, strong $A$-preferers and strong $\bar{A}$-preferers in the population. For the three cases the results can be found in Table 2 . The percentages are computed by means of a series expansion of the incomplete beta function (Abramowitz and Stegun, 1968, equation 26.5.4).

\section{TABLE 2}

Percentages of different categories of preferers in the population for three cases, all with $E p=0.60$

\begin{tabular}{lccc}
\hline & $\begin{array}{c}\text { Net A-preferers } \\
(\%)\end{array}$ & $\begin{array}{c}\text { Strong A-preferers } \\
(\%)\end{array}$ & $\begin{array}{c}\text { Strong A-preferers } \\
(\%)\end{array}$ \\
\hline Case I & 92 & 1 & 0 \\
Case II & 69 & 26 & 5 \\
Case III & 61 & 47 & 27 \\
\hline
\end{tabular}




\section{Estimation of the Parameters in an Empirical Product Test Situation}

In the previous section we demonstrated the use of the beta distribution for three hypothetical cases. Now we want to estimate the parameters of the beta distribution from empirical data, and, for this purpose, we propose the following pairwise comparison product test with replication.

Suppose we want to test two products $A$ and $B$ against one another. Let every subject be submitted twice to a product test, where the alternatives in both tests are the same. There should be some time between the tests to prevent conditioning, the order of presentation should be varied and the subjects must be unaware of the fact that the alternatives in the second test are the same as in the first. Because of the last condition, the test products should not have very striking features, thus enabling recognition.

After all subjects have completed the test, two quantities can be computed:

$f_{1}=$ the fraction of the total number of subjects who preferred $A$ once and $\bar{A}$ once,

$f_{2}=$ the fraction of the total number of subjects who preferred $A$ both times.

With respect to $f_{2}$ we note that the likelihood that a subject with probability $p$ chooses $A$ in both cases is $p^{2}$. So the expected value of the fraction of the whole population who prefers $A$ twice is

$$
\int_{0}^{1} p^{2} b(p) \mathrm{d} p=\mu_{2}
$$

the second moment of the beta distribution, and $f_{2}$ is an unbiased estimator for $\mu_{2}$.

In an analogous way for $f_{1}$, we find that the probability for a subject with parameter $p$ to choose $A$ once and $\bar{A}$ once $=2 p(1-p)$. Therefore $f_{1}$ is an unbiased estimator for $2\left(\mu_{1}-\mu_{2}\right)$.

Now when $f_{1}$ and $f_{2}$ are known, estimates for the first two moments of the beta distribution can be obtained from

$$
f_{1}=2\left(\hat{\mu}_{1}-\hat{\mu}_{2}\right)
$$

and

$$
f_{2}=\hat{\mu}_{2}
$$

where $\hat{\mu}_{1}$ and $\hat{\mu}_{2}$ are the respective estimates.

From $\hat{\mu}_{1}$ and $\hat{\mu}_{2}$, estimates for the parameters of the beta distribution can be found. For this purpose (6) and (7) are written in another way. The expressions for the estimates $\hat{a}$ and $\hat{b}$ are

$$
\begin{aligned}
& \hat{a}=\frac{\hat{\mu}_{1}^{2}-\hat{\mu}_{1} \hat{\mu}_{2}}{\hat{\mu}_{1}-\hat{\mu}_{1}^{2}}, \\
& \hat{b}=\frac{\hat{a}\left(1-\hat{\mu}_{1}\right)}{\hat{\mu}_{1}} .
\end{aligned}
$$

After estimation of $a$ and $b$ the density function $b(p)$ can be plotted to give a picture of the preference distribution over the population. To make the interpretation easier, a presentation like that in Table 2 may be useful.

Of course, $\hat{\mu}_{1}$ and $\hat{\mu}_{2}$ are not dependent on the beta distribution assumption and their values are also interesting in themselves because the variance of $p$ can be derived from them. 


\section{ACCURACY OF THE Estimates}

It is useful to know the accuracy of the estimates discussed in the previous section. It is clear that this accuracy depends on the variance of $f_{1}$ and $f_{2}$, which in turn depends on the distribution of $p$ and the same size $N$. In this section, we derive expressions for the variance of $f_{1}, f_{2}, \hat{\mu}_{1}$ and $\hat{\mu}_{2}$ which can be evaluated when the true values $a$ and $b$ of the beta distribution for $p$ are known. Because $\hat{\mu}_{1}$ and $\hat{\mu}_{2}$ determine $\hat{a}$ and $\hat{b}$ (equations (12) and (13)), the variances of $\hat{\mu}_{1}$ and $\hat{\mu}_{2}$ are important for the accuracy of $\hat{a}$ and $\hat{b}$, but direct expressions for var $\hat{a}$ and $\operatorname{var} \hat{b}$ are difficult, as a consequence of the rather complicated expressions (12) and (13).

Let $s_{i}$ be a random variate, which takes the value 1 if subject $i$-with probability to prefer $A=p$-prefers $A$ once and $\bar{A}$ once, and 0 otherwise. Then we have the following possibilities for the values of $s_{i}$ and $s_{i}^{2}$ with the corresponding probabilities:

$$
\begin{array}{c|c|l}
s_{i} & s_{i}^{2} & \text { probability } \\
1 & 1 & 2 p(1-p) \\
0 & 0 & 1-2 p(1-p)
\end{array}
$$

So

$$
E s_{i}=E s_{i}^{2}=2 p(1-p)
$$

and

$$
\operatorname{var} s_{i}=E s_{i}^{2}-\left(E s_{i}\right)^{2}=2 p-6 p^{2}+8 p^{3}-4 p^{4} .
$$

When we now take the more general position that the probability that subject $i$ will prefer $A$ is a drawing from a beta distribution with p.d.f. $b(p)$, we get

$$
\begin{aligned}
\operatorname{var} s_{i} & =\int_{0}^{1}\left(2 p-6 p^{2}+8 p^{3}-4 p^{4}\right) b(p) d p \\
& =2 \mu_{1}-6 \mu_{2}+8 \mu_{3}-4 \mu_{4} .
\end{aligned}
$$

Now from the definition of $s_{i}$ follows:

$$
f_{1}=\left(\Sigma s_{i}\right) / N,
$$

and because different subjects determine their preferences independent of each other:

$$
\operatorname{var}^{\prime} f_{1}=\left(\operatorname{var} s_{i}\right) / N=\left(2 \mu_{1}-6 \mu_{2}+8 \mu_{3}-4 \mu_{4}\right) / N \text {. }
$$

We define $t_{i}$ as a random variate, which takes the value 1 if test person $i$, whose probability $p$ is a drawing from a beta distribution with p.d.f. $b(p)$, prefers $A$ twice and 0 otherwise. Then in the same way as the foregoing, we can derive that

Now,

$$
\operatorname{var} t_{i}=\mu_{2}-\mu_{4} \text {. }
$$

therefore

$$
f_{2}=\left(\sum t_{i}\right) / N
$$

$$
\operatorname{var} f_{2}=\left(\mu_{2}-\mu_{4}\right) / N
$$

Let

$$
v_{i} \stackrel{\text { def }}{=} s_{i}+t_{i},
$$


so $v_{i}$ takes the value 0 if subject $i$ prefers $A$ twice and 1 otherwise. For the possible values of $v_{i}$ and $v_{i}^{2}$ we then have

So

$$
\begin{array}{l|c|l}
v_{i} & v_{i}^{2} & \text { probability } \\
1 & 1 & 1-(1-p)^{2}=2 p-p^{2} \\
0 & 0 & (1-p)^{2}
\end{array}
$$

and

$$
E v_{i}=E v_{i}^{2}=2 p-p^{2}
$$

When

$$
\operatorname{var} v_{i}=2 \mu_{1}-5 \mu_{2}+4 \mu_{3}-\mu_{4}
$$

$$
\begin{gathered}
f_{12} \stackrel{\text { def }}{=}\left(\sum v_{i} / N\right), \\
\operatorname{var} f_{12}=\left(2 \mu_{1}-5 \mu_{2}+4 \mu_{3}-\mu_{4}\right) / N .
\end{gathered}
$$

Because of (16) and the definition of $f_{12}$ :

therefore

$$
f_{12}=f_{1}+f_{2}
$$

$$
\operatorname{cov}\left(f_{1}, f_{2}\right)=\left(\operatorname{var} f_{12}-\operatorname{var} f_{1}-\operatorname{var} f_{2}\right) / 2
$$

Now, from the variances of $f_{1}$ and $f_{2}$ and $\operatorname{cov}\left(f_{1}, f_{2}\right)$, the variances of $\hat{\mu}_{1}$ and $\hat{\mu}_{2}$ can be derived. From (10) and (11) we have

so

$$
\begin{aligned}
& \hat{\mu}_{1}=f_{2}+\frac{1}{2} f_{1}, \\
& \hat{\mu}_{2}=f_{2} ;
\end{aligned}
$$

$$
\begin{aligned}
& \operatorname{var} \hat{\mu}_{1}=\operatorname{var} f_{2}+\frac{1}{4} \operatorname{var} f_{1}+\operatorname{cov}\left(f_{1}, f_{2}\right), \\
& \operatorname{var} \hat{\mu}_{2}=\operatorname{var} f_{2} .
\end{aligned}
$$

For a specific beta distribution with given parameters $a$ and $b$ the moments $\mu_{1}, \mu_{2}, \ldots$ can be found by means of (6)-(8). Then, for a given sample size $N$ : $\operatorname{var} f_{1}, \operatorname{var} f_{2}$ and $\operatorname{cov}\left(f_{1}, f_{2}\right)$ can be computed with (14), (15), (17) and (18). After that by means of (19) and (20) var $\hat{\mu}_{1}$ and var $\hat{\mu}_{2}$ can be obtained.

To give an idea about the accuracy of the estimated moments, we give in Table 3 the standard deviations of $\hat{\mu}_{1}$ and $\hat{\mu}_{2}$, computed in the way just described, for a number of combinations of $a$ and $b$ when the sample size is 100 . For sample size $100 x$ the standard deviation is $1 / \sqrt{ } x$ times the corresponding value for sample size 100 . In an empirical product test situation, the true values of $a$ and $b$ are of course unknown. Therefore we cannot use Table 3 to produce exact standard deviations for $\hat{\mu}_{1}$ and $\hat{\mu}_{2}$, but an approximation of these standard deviations can be obtained by entering Table 3 with the estimated parameters $\hat{a}$ and $\hat{b}$. Moreover, the figures in Table 3 are useful to know the order of magnitude of the standard deviations. It appears, for example, that for $N=100$ almost all standard deviations lie between 0.01 and 0.05 , which constitutes useful general information when $a$ and $b$ are not known. 
TABLE 3

Computed standard deviations of the estimators $\hat{\mu}_{1}$ and $\hat{\mu}_{2}$ for a number of values of $a$ and $b$, parameters of the beta distribution for $p ; N=100$

\begin{tabular}{|c|c|c|c|c|c|c|c|c|c|c|c|c|c|}
\hline \multirow[b]{2}{*}{$a$} & \\
\hline & $S D$ & $0 \cdot 1$ & 0.5 & 1 & 2 & 3 & 4 & 5 & 6 & 7 & 8 & 9 & 10 \\
\hline & $\begin{array}{l}\mu_{1} \\
\mu_{2}\end{array}$ & & & & & & & & & $\begin{array}{l}0.008 \\
0.004\end{array}$ & $\begin{array}{l}0.007 \\
0.004\end{array}$ & $\begin{array}{l}0.007 \\
0.003\end{array}$ & $\begin{array}{l}0.007 \\
0.003\end{array}$ \\
\hline .5 & $\begin{array}{l}\mu_{1} \\
\mu_{2}\end{array}$ & $\begin{array}{l}0.016 \\
0.023\end{array}$ & $\begin{array}{l}0.025 \\
0.032\end{array}$ & $\begin{array}{l}0.026 \\
0.030\end{array}$ & & & & & & & & & $\begin{array}{l}0.014 \\
0.008\end{array}$ \\
\hline 1 & $\begin{array}{l}\mu_{1} \\
\mu_{2}\end{array}$ & 0.015 & & & & & & & & & & & $\begin{array}{l}0.020 \\
0.012\end{array}$ \\
\hline 2 & $\begin{array}{l}\mu_{1} \\
\mu_{2}\end{array}$ & & & & & & & & & & & & $\begin{array}{l}0.025 \\
0.019\end{array}$ \\
\hline 3 & $\begin{array}{l}\mu_{1} \\
\mu_{2}\end{array}$ & & & & & & & & & & & & $\begin{array}{l}0.029 \\
0.024\end{array}$ \\
\hline 4 & $\begin{array}{l}\mu_{1} \\
\mu_{2}\end{array}$ & & & & & & & & & & & & $\begin{array}{l}0.031 \\
0.028\end{array}$ \\
\hline 5 & $\begin{array}{l}\mu_{1} \\
\mu_{2}\end{array}$ & & & $\begin{array}{l}0.024 \\
0.040\end{array}$ & $\begin{array}{l}0.030 \\
0.045\end{array}$ & & $\begin{array}{l}0.033 \\
0.044\end{array}$ & & & $\begin{array}{l}0.034 \\
0.038\end{array}$ & $\begin{array}{l}0.033 \\
0.036\end{array}$ & & $\begin{array}{l}0.032 \\
0.032\end{array}$ \\
\hline 6 & $\begin{array}{l}\mu_{1} \\
\mu_{2}\end{array}$ & $\begin{array}{l}0.008 \\
0.015\end{array}$ & $\begin{array}{l}0.018 \\
0.031\end{array}$ & $\begin{array}{l}0.023 \\
0.039\end{array}$ & $\begin{array}{l}0.029 \\
0.045\end{array}$ & & $\begin{array}{l}0.033 \\
0.045\end{array}$ & & & & & & $\begin{array}{l}0.033 \\
0.035\end{array}$ \\
\hline 7 & $\begin{array}{l}\mu_{1} \\
\mu_{2}\end{array}$ & 0.008 & $\begin{array}{l}0.017 \\
0.029\end{array}$ & & $\begin{array}{l}0.028 \\
0.045\end{array}$ & & & & & & & & $\begin{array}{l}0.034 \\
0.037\end{array}$ \\
\hline 8 & $\begin{array}{l}\mu_{1} \\
\mu_{2}\end{array}$ & & 0.016 & $\begin{array}{l}0.021 \\
0.037\end{array}$ & $\begin{array}{l}0.027 \\
0.044\end{array}$ & & & & & $\begin{array}{l}0.034 \\
0.044\end{array}$ & & & $\begin{array}{l}0.034 \\
0.039\end{array}$ \\
\hline 9 & $\begin{array}{l}\mu_{1} \\
\mu_{2}\end{array}$ & & & $\begin{array}{l}0.020 \\
0.036\end{array}$ & $\begin{array}{l}0.026 \\
0.043\end{array}$ & & $\begin{array}{l}0.031 \\
0.047\end{array}$ & & $\begin{array}{l}0.034 \\
0.046\end{array}$ & $\begin{array}{l}0.034 \\
0.045\end{array}$ & $\begin{array}{l}0.034 \\
0.044\end{array}$ & $\begin{array}{l}0.034 \\
0.043\end{array}$ & $\begin{array}{l}0.034 \\
0.041\end{array}$ \\
\hline 10 & $\begin{array}{l}\mu_{1} \\
\mu_{2}\end{array}$ & $\begin{array}{l}0.007 \\
0.013\end{array}$ & $\begin{array}{l}0.014 \\
0.026\end{array}$ & $\begin{array}{l}0.020 \\
0.035\end{array}$ & $\begin{array}{l}0.025 \\
0.043\end{array}$ & $\begin{array}{l}0.029 \\
0.046\end{array}$ & $\begin{array}{l}0.031 \\
0.047\end{array}$ & $\begin{array}{l}0.032 \\
0.047\end{array}$ & $\begin{array}{l}0.033 \\
0.047\end{array}$ & $\begin{array}{l}0.034 \\
0.046\end{array}$ & $\begin{array}{l}0.034 \\
0.045\end{array}$ & $\begin{array}{l}0.034 \\
0.044\end{array}$ & $\begin{array}{l}0.035 \\
0.043\end{array}$ \\
\hline
\end{tabular}

\section{Evaluating the Fit of the Beta Distribution}

When there are doubts about the fit of the beta distribution in a particular situation, one may wish to extend the test by asking each subject to state his preference three times; it is then possible to estimate the third moment of the beta distribution.

The expected fraction of subjects who prefer $A$ three times is

$$
\int_{0}^{1} p^{3} b(p) d p=\mu_{3}
$$

so with the fraction of subjects who prefer $A$ three times we have an estimator for $\mu_{3}$, which is denoted as $\hat{\mu}_{3}$. With this third moment we have the means to check the appropriateness of the beta distribution: with the aid of $\hat{\mu}_{1}$ and $\hat{\mu}_{2}$ we can compute the estimates $\hat{a}$ and $\hat{b}$ and then (with (8)) the third moment. This computed values for $\mu_{3}$, denoted as $\mu_{3}^{*}$, can be compared with $\hat{\mu}_{3}$. If the beta distribution fit is satisfactory these two values should not differ much. An indication of the size of this difference can be obtained by comparing it with the standard deviation of $\hat{\mu}_{3}$. In the same way as was 
followed in Section 8 to derive the variances of $\hat{\mu}_{1}$ and $\hat{\mu}_{2}$, it can be found that

$$
\operatorname{var} \hat{\mu}_{3}=\left(\mu_{3}-\mu_{6}\right) / N \text {. }
$$

Again in an empirical situation we do not know the exact value of var $\hat{\mu}_{3}$, because the true values of $a$ and $b$ are not known, but by using $\hat{a}$ and $\hat{b}$ an approximation can be obtained.

\section{Application on Data}

The 12 replicated product tests, discussed in Section 5, provide us with the empirical data for an application of the beta distribution approach.

We can look at every test in two different ways:

(a) We examine the alternative, called $A$, and divide the responses into $A$ and $\bar{A}$. In doing so, we consider the distribution of the probability to prefer $A$.

(b) We examine the alternative $B$ and divide the responses into $B$ and $\bar{B}$. Now we study the probability to prefer $B$.

One is usually more interested in one of the test products (for example the own brand) and finding the preference distribution for that alternative may be sufficient. For completeness, we give in Table 4 the results for the two approaches just mentioned.

TABLE 4

Results of 12 product tests

\begin{tabular}{|c|c|c|c|c|c|c|c|c|c|}
\hline $\begin{array}{l}\text { Test } \\
\text { No. }\end{array}$ & $\begin{array}{l}\text { Fixed } \\
\text { alternative } \\
(X)\end{array}$ & $\hat{\mu}_{1}$ & $\hat{\mu}_{2}$ & $\hat{a}$ & $\hat{b}$ & $\begin{array}{c}\text { Net } \\
X \text {-preferers } \\
(p \geqslant 0 \cdot 50) \\
(\%)\end{array}$ & $\begin{array}{c}\text { Strong } \\
X \text {-preferers } \\
(p \geqslant 0.75) \\
(\%)\end{array}$ & $\begin{array}{c}\text { Strong } \\
X \text {-preferers } \\
(p \leqslant 0 \cdot 25) \\
(\%) \\
\end{array}$ & $\begin{array}{c}\text { Sample } \\
\text { size }\end{array}$ \\
\hline 1 & $\begin{array}{l}A \\
B\end{array}$ & $\begin{array}{l}0.435 \\
0.415\end{array}$ & $\begin{array}{l}0 \cdot 240 \\
0 \cdot 200\end{array}$ & $\begin{array}{l}1 \cdot 67 \\
3 \cdot 21\end{array}$ & $\begin{array}{l}2 \cdot 17 \\
4 \cdot 53\end{array}$ & $\begin{array}{l}39 \\
31\end{array}$ & $\begin{array}{r}10 \\
3\end{array}$ & $\begin{array}{l}24 \\
17\end{array}$ & $\begin{array}{l}100 \\
100\end{array}$ \\
\hline 2 & $\begin{array}{l}A \\
B\end{array}$ & $\begin{array}{l}0.337 \\
0.594\end{array}$ & $\begin{array}{l}0 \cdot 178 \\
0 \cdot 416\end{array}$ & $\begin{array}{l}0.82 \\
1.68\end{array}$ & $\begin{array}{l}1 \cdot 62 \\
1 \cdot 15\end{array}$ & $\begin{array}{l}27 \\
64\end{array}$ & $\begin{array}{r}8 \\
33\end{array}$ & $\begin{array}{l}45 \\
11\end{array}$ & $\begin{array}{l}101 \\
101\end{array}$ \\
\hline 3 & $\begin{array}{l}A \\
B\end{array}$ & $\begin{array}{l}0.360 \\
0.460\end{array}$ & $\begin{array}{l}0 \cdot 200 \\
0 \cdot 280\end{array}$ & $\begin{array}{l}0.82 \\
1.21\end{array}$ & $\begin{array}{l}1 \cdot 45 \\
1 \cdot 42\end{array}$ & $\begin{array}{l}30 \\
44\end{array}$ & $\begin{array}{l}11 \\
17\end{array}$ & $\begin{array}{l}42 \\
26\end{array}$ & $\begin{array}{l}100 \\
100\end{array}$ \\
\hline 4 & $\begin{array}{l}A \\
B\end{array}$ & $\begin{array}{l}0.360 \\
0.404\end{array}$ & $\begin{array}{l}0 \cdot 155 \\
0 \cdot 180\end{array}$ & $\begin{array}{l}2 \cdot 90 \\
5 \cdot 27\end{array}$ & $\begin{array}{l}5 \cdot 14 \\
7 \cdot 78\end{array}$ & $\begin{array}{l}20 \\
76\end{array}$ & $\begin{array}{l}1 \\
0\end{array}$ & $\begin{array}{l}27 \\
12\end{array}$ & $\begin{array}{l}161 \\
161\end{array}$ \\
\hline 5 & $\begin{array}{l}A \\
B\end{array}$ & $\begin{array}{l}0.570 \\
0.295\end{array}$ & $\begin{array}{l}0 \cdot 430 \\
0 \cdot 150\end{array}$ & $\begin{array}{l}0.76 \\
0.68\end{array}$ & $\begin{array}{l}0.57 \\
1.62\end{array}$ & $\begin{array}{l}59 \\
22\end{array}$ & $\begin{array}{r}38 \\
7\end{array}$ & $\begin{array}{l}23 \\
53\end{array}$ & $\begin{array}{l}100 \\
100\end{array}$ \\
\hline 6 & $\begin{array}{l}A \\
B\end{array}$ & $\begin{array}{l}0.544 \\
0.272\end{array}$ & $\begin{array}{l}0 \cdot 394 \\
0 \cdot 131\end{array}$ & $\begin{array}{l}0.83 \\
0.67\end{array}$ & $\begin{array}{l}0.70 \\
1.79\end{array}$ & $\begin{array}{l}56 \\
19\end{array}$ & $\begin{array}{r}33 \\
5\end{array}$ & $\begin{array}{l}24 \\
56\end{array}$ & $\begin{array}{l}160 \\
160\end{array}$ \\
\hline 7 & $\begin{array}{l}A \\
B\end{array}$ & $\begin{array}{l}0.441 \\
0.400\end{array}$ & $\begin{array}{l}0 \cdot 250 \\
0 \cdot 219\end{array}$ & $\begin{array}{l}1 \cdot 50 \\
1 \cdot 23\end{array}$ & $\begin{array}{l}1.91 \\
1.85\end{array}$ & $\begin{array}{l}40 \\
34\end{array}$ & $\begin{array}{l}12 \\
10\end{array}$ & $\begin{array}{l}25 \\
32\end{array}$ & $\begin{array}{l}160 \\
160\end{array}$ \\
\hline 8 & $\begin{array}{l}A \\
B\end{array}$ & $\begin{array}{l}0.305 \\
0.565\end{array}$ & $\begin{array}{l}0 \cdot 120 \\
0 \cdot 360\end{array}$ & $\begin{array}{l}2 \cdot 09 \\
2 \cdot 84\end{array}$ & $\begin{array}{l}4 \cdot 77 \\
2 \cdot 19\end{array}$ & $\begin{array}{l}13 \\
62\end{array}$ & $\begin{array}{r}1 \\
21\end{array}$ & $\begin{array}{r}42 \\
7\end{array}$ & $\begin{array}{l}100 \\
100\end{array}$ \\
\hline 9 & $\begin{array}{l}A \\
B\end{array}$ & $\begin{array}{l}0.700 \\
0.205\end{array}$ & $\begin{array}{l}0.570 \\
0.090\end{array}$ & $\begin{array}{l}1 \cdot 14 \\
0 \cdot 49\end{array}$ & $\begin{array}{l}0.49 \\
1.91\end{array}$ & $\begin{array}{l}75 \\
12\end{array}$ & $\begin{array}{r}54 \\
3\end{array}$ & $\begin{array}{l}10 \\
68\end{array}$ & $\begin{array}{l}100 \\
100\end{array}$ \\
\hline 10 & $\begin{array}{l}A \\
B\end{array}$ & $\begin{array}{l}0.645 \\
0.250\end{array}$ & $\begin{array}{l}0 \cdot 500 \\
0 \cdot 130\end{array}$ & $\begin{array}{l}1 \cdot 11 \\
0 \cdot 44\end{array}$ & $\begin{array}{l}0.61 \\
1.33\end{array}$ & $\begin{array}{l}69 \\
19\end{array}$ & $\begin{array}{r}46 \\
7\end{array}$ & $\begin{array}{l}13 \\
61\end{array}$ & $\begin{array}{l}100 \\
100\end{array}$ \\
\hline 11 & $\begin{array}{l}A \\
B\end{array}$ & $\begin{array}{l}0.340 \\
0.375\end{array}$ & $\begin{array}{l}0 \cdot 210 \\
0 \cdot 270\end{array}$ & $\begin{array}{l}0.47 \\
0.30\end{array}$ & $\begin{array}{l}0.91 \\
0.51\end{array}$ & $\begin{array}{l}30 \\
36\end{array}$ & $\begin{array}{l}15 \\
23\end{array}$ & $\begin{array}{l}50 \\
50\end{array}$ & $\begin{array}{l}100 \\
100\end{array}$ \\
\hline 12 & $\begin{array}{l}A \\
B\end{array}$ & $\begin{array}{l}0.315 \\
0.460\end{array}$ & $\begin{array}{l}0.130 \\
0 \cdot 310\end{array}$ & $\begin{array}{l}1 \cdot 89 \\
0 \cdot 70\end{array}$ & $\begin{array}{l}4 \cdot 12 \\
0 \cdot 82\end{array}$ & $\begin{array}{l}16 \\
45\end{array}$ & $\begin{array}{r}1 \\
24\end{array}$ & $\begin{array}{l}41 \\
33\end{array}$ & $\begin{array}{l}100 \\
100\end{array}$ \\
\hline
\end{tabular}


For every case we report: the estimated moments $\hat{\mu}_{1}$ and $\hat{\mu}_{2}$, the estimates for the beta parameters $\hat{a}$ and $\hat{b}$ and the percentages of the consumers who are net $X$-preferers, strong $X$-preferers and strong $\bar{X}$-preferers, where $X$ stands for the alternative concerned. The latter quantities, which are derived as in Section 6 , give an idea about the preference distribution.

By inspection of the values for $\hat{a}$ and $\hat{b}$ in Table 4 we see that almost all types of beta distribution are present: U-shaped, inverse $U$-shaped, J-shaped and inverse $\mathrm{J}$-shaped. For marketing policy, the most interesting figures seem to be the percentages of the different categories of preferers in the population. The importance of the information this type of analysis can provide is once more demonstrated if one compares, for example, the results of the tests $4 B$ and $7 B$. We see for both cases that the expected fraction of subjects who prefer $B$ in a product test is $0 \cdot 40$. Yet the preference distributions are quite different. In the first case, there are few consumers with strong preferences either for $B$ or $\bar{B}$ whereas in the second case their percentage is quite considerable. This kind of informations will have its impact on marketing policy. Because the subjects were asked to state their preferences only twice, the check-with the aid of the third moment-to determine the measure to which the beta distribution fits the preference distribution could not be carried out for these data.

\section{CONCLUSION}

A probabilistic interpretation of personal preferences reflects empirical reality. This being the case, insight into the preference structure can be enriched by knowing the distribution of preference in the population. When this distribution may be approached by a beta distribution, the necessary information about the preference distribution can be obtained by a pairwise product test with replication.

\section{ACKNOWLEDGEMENTS}

The author wishes to thank SOCMAR N.V. for providing the data, Mr J. A. Bijkerk for his assistance in the computations and the referees for some useful suggestions, including those regarding the English text.

\section{REFERENCES}

AAKer, D. A. (1971). The new trier stochastic model of brand choice, Manag. Sci., 17, 435-450. Abramowitz, M. A. and Stegun, I. A. (eds). (1968). Handbook of Mathematical Functions. New York: Dover Publications.

David, H. A. (1963). The Method of Paired Comparisons. London: Griffin.

DAY, R. L. (1965). Systematic paired comparisons in preference analysis. J. Marketing Res., 2, 406-412.

HowARD, R. A. (1968). Stochastic models of consumer behavior. In Application of the Sciences in Marketing Management (Bass et al., eds). New York: Wiley.

Kendall, M. G. and Stuart, A. (1969). The Advanced Theory of Statistics, Vol. 1. London: Griffin.

Massy, W. F., Montgomery, D. B. and Morrison, D. G. (1970). Stochastic Models of Buying Behaviour, Ch. 3. Cambridge, Mass.: M.I.T. Press. 